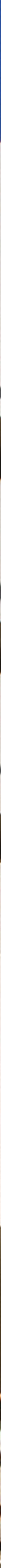



JM IS A SCHOOL
ARNS TO COMMUNICATE 


\title{
Introducción a la leyenda del artista
}

Natalia Domínguez / Universidad Politécnica de Valencia

\begin{abstract}
Resumen:
Este artículo analiza cómo, durante la historia del arte, diferentes dispositivos han ayudado a infundir la figura del artista como genio, basándose principalmente en la mitificación de elementos biográficos y en la concepción del artista tocado por la divinidad. Este estudio previo sirve posteriormente para analizar dos periodos concretos y antagónicos de la historia del siglo XX: la modernidad, que ayudó a corroborar tales construcciones a través de la disolución entre artista y público; y la aparición del arte conceptual durante la posmodernidad como paradigma del cuestionamiento de prácticas como la desmaterialización y la desespecificación, que ayudaron a cuestionar las ideas de autoría, originalidad y genialidad.
\end{abstract}

En una ocasión, un compañero me comentó que Christo, al principio de su carrera, mandó una serie de paquetes envueltos a sus amigos para felicitar las Navidades. Una vez abierto, en su interior se descubría una nota que decía "Enhorabuena, acabas de destruir un Christo". Recuerdo que nos reímos y acepté la historia de buena gana sin cuestionar su procedencia. Ahora que lo hago, él es incapaz de facilitarme su origen, y bibliográficamente hablando, los únicos datos que corroboran dicho suceso no van más allá de una serie poco precisa de conexiones interpersonales. Es bastante probable, además, que la historia haya sufrido pequeñas variaciones desde su creación hasta el momento en el que la conocí.

Consecuentemente, podríamos hablar aquí de un adorno histórico cuya veracidad desconocemos, una anécdota convertida en hecho; o lo que es lo mismo: la creación de un mito.

Independientemente de la veracidad o falsedad de tal historia - estudio que se escapa de la preocupación central del texto-, llama la atención cómo la Historia del Arte contiene infinidad de anécdotas más o menos creíbles inscritas en las biografías de múltiples artistas que, debido a su repetición y difusión, han sentado las bases de lo que socialmente entendemos cuando nos referimos al término artista. De este modo, el cometido de esta reflexión es el estudio histórico de la construcción de tal imaginario para llegar a entender, por un lado, el origen de la leyenda del artista, y por otro, la necesidad de desmitificación que el arte conceptual llevó consigo desde finales de la década de 1960 y durante los años setenta, valiéndose de recursos tales como la desespecialización y la desmaterialización del objeto artístico, entre otros.

Para ello, partiremos de las consideraciones expuestas por Ernst Kris y Otto Kurz sobre la mitificación de la figura del artista en su ensayo La leyenda del artista, cuyo principal cometido fue el estudio de las formulas biográficas narradas durante la Antigüedad Clásica y el Renacimiento ${ }^{2}$ para establecer así una serie de pautas que pretenden justificar la forma en la que, sociológicamente hablando, juzgamos la figura del artista. Tales afirmaciones servirán de apoyo teórico a la hora de enfrentarnos, cuatro siglos más tarde, a la autonomía que el arte por el arte llevó consigo, apareciendo tímidamente a finales del siglo XIX y posicionándose como filosofía reinante durante las vanguardias históricas que, según la opinión de Suzi Gablik en su libro ¿Ha muerto el arte moderno?33, disolvió los lazos entre artista y público. Treinta años más tarde, aproximadamente, y basándome en a las opiniones de Lucy Lippard en su libro Seis años: La desmaterialización del objeto artístico desde 1966 a 1972, la mercantilización del objeto artístico llevó consigo una serie de prácticas artísticas posteriormente conocidas como Arte Conceptual que pretendieron replantear la actividad del artista como productor y del arte como producto.

3 Como dato de interés, creo conveniente comentar cómo E. Kris y O. Kurz hacen hincapié en el hecho de que la figura del artista independiente, constituida a partir de los siglos XIV y XV (finales de la baja Edad Media e inicios del Renacimiento) y que tomamos como definición contemporánea de artista, está fuertemente inspirada en relatos originales sobre artistas griegos, primer momento del que se tiene constancia de la firma del artista y de la biografía como género literario en KRIS, E. \& KURZ, O. La leyenda del artista. Ensayos Arte Cátedra. Madrid, 2010.

4 GABLIK, S. ¿Ha muerto el arte moderno? Herman Blume. Madrid, 1987. 


\section{Abstract:}

This article analyses how, throughout art history, different devices have helped to arose the figure of the artist as a genius, fundamentally by the mystification of some biographic elements and the conception of the artist as a divine entity. The initial study will subsequently help to examine two very precise and antagonistic periods during the XX century: Modernism, which helped to promote those conceptions by the dissolution between the artist and the audience; and the birth of conceptual art during Post-modernism as a paradigm from which to question artistic practices such dematerialization and de-specialisation, helping to wonder about authority, originality and genius.

\section{Preamble to the legend of the artist}

\section{La definición de artista}

Revisando a los maestros del Renacimiento, uno puede darse cuenta de cómo la fama y el reconocimiento del artista están rodeados de un halo de misticismo que los posiciona como seres prodigiosos tocados por un don mágico e inexplicable, cuyo renombre ha aprendido a sobrevivir a cualquiera de sus obras. Pero asombra aún más si retrocedemos hasta la Antigüedad Clásica, ya que descubrimos cómo la fama de varios artistas griegos se consolidara sólo y exclusivamente a partir de sus biografías, en las que se les reconoce como personajes excepcionales cuyas aptitudes se desarrollaron desde su más temprana infancia, pero de los que, a su vez, no se conservan obras ni documentos que nos permitan formarnos otra impresión. E. Kris y O. Kurz afirman que este hecho se fundamenta en la poderosa influencia que las biografías - y consecuentemente, los biógrafos, entre los que no podemos olvidar a Plinio el Viejo y Vasari- han ejercido desde la Grecia Clásica, asentándose definitivamente como género independiente durante el Renacimiento, y que se ha venido arrastrando hasta nuestro presente. A raíz de esto comentan:

"En los numerosos relatos de vidas de pintores y escultores que nos han llegado del Renacimiento en adelante, siempre encontramos asuntos típicos (temas que se reparten en numerosas biografías con poca o ninguna variación) relacionados bien con la carrera del artista (sobre todo con su niñez) o bien con el efecto de sus obras en su público."4
Esta afirmación sostiene, además, que «a partir del momento en el que el artista hace su aparición en los documentos históricos, algunas nociones estereotipadas fueron relacionadas con su obra y persona (prejuicios que no han perdido nunca por completo su significado y que siguen influyendo en nuestro juicio de lo que es un artista $)^{5}$. Teniendo en cuenta estas afirmaciones y la consideración de que "el que perdure o no el nombre de un artista depende, no de la grandeza y perfección de su logro artístico —incluso si éste pudiese ser probado objetivamente-, sino del significado ligado a la obra de arte" 6 , veo oportuno remarcar dos puntos interesantes. Por un lado, que la genialidad del artista no reside en su habilidad o don creativo, sino en qué entendemos por arte; y por otro, que éste se nos presenta como construcción cultural que tiene su razón de ser en la figura del biógrafo y que se genera a partir de lo que Hal Foster denominara acción diferida, término definido en su libro El retorno de lo real. La vanguardia a finales de siglo, en el que el autor se apropia de este concepto de origen freudiano diciendo así:

"En Freud un acontecimiento se registra como traumático únicamente si hay un acontecimiento posterior que lo recodifica retroactivamente, en acción diferida. Aquí yo propongo que la significación de los acontecimientos de vanguardia se produce de un modo análogo, mediante una compleja alternancia de anticipación y reconstrucción." 
Aunque el uso de la acepción le sirve a Foster para justificar su perspectiva sobre el surgimiento de la vanguardia con respecto a su pasado, existe una analogía entre esta anticipación y reconstrucción de la que habla que es la que me interesa extrapolar al concepto de biografía, ya que permite afirmar que toda narración se genera una vez conocidas sus consecuencias históricas (en este caso, la genialidad probada del artista a través de su fama), siendo fácil, consecuentemente, recrear un inicio cualquiera para justificar un fin concreto.

Si somos capaces de afirmar aquí tales consideraciones habremos llegado al primero de mis cometidos, que pretende dejar claro que las fórmulas biográficas se crean a partir de la mitificación de la anécdota y el uso de recursos recogidos en la literatura épica y sacra, en las que el biógrafo y la «necesidad de la sociedad de hallar un acceso a la figura excepcional y superdotada $»^{8}$ del artista juegan un papel crucial.

Aunque por falta de tiempo y sentido - veo innecesario redundar en la investigación de E. Kris y O. Kurz- haré sólo un recorrido superficial a través del bagaje histórico que define la construcción social de la figura del artista-genio ${ }^{9}$, creo conveniente recopilar las características principales que se encuentran en la mayoría de las biografías para ayudar a un mejor entendimiento de los factores que han mitificado la concepción del artista. De este modo, si tenemos en cuenta su análisis realizado sobre las obras de biógrafos que dedicaron su carrera a narrar las peripecias artísticas de los maestros de la Antigüedad Clásica y el Renacimiento, nos daremos cuenta de la existencia de dos factores que se repiten continuamente a la hora de definir al artista. Uno de ellos es la importancia que damos a la niñez de las personas excepcionales, que surge de la consideración de lo hereditario como signo premonitorio y de los fundamentos de la psicología moderna que sostienen que "los acontecimientos de la infancia tienen una importancia decisiva para el futuro desarrollo del hombre"10. El otro se basa en la construcción de la anécdota centrada en la descripción del artista como ser superior a las consideraciones mundanas.

Aunque ambas condiciones se retroalimentan de manera evidente, empezaré por definir la primera de ellas, que creo de mayor importancia: aquella que sostiene que el artista nace artista. En este ámbito, E. Kris y O. Kurz llegan a la conclusión de que existen fórmulas biográficas que se repiten y que responden de la siguiente manera: en primer lugar, existe la figura central del niño prodigio, que muestra un talento innato que lucha temprana y fervientemente por expresarse; de manera secundaria — aunque crucial- aparece la figura del descubridor o mecenas (casualmente, alguien de mayor rango social) que consciente o inconsciente fomentará el florecimiento y desarrollo de tal talento. La suma de ambos factores generarán el artista legendario. Pero prestemos atención a la figura del niño prodigio. Este, tal y como he comentado, es un ser que posee un don sólo accesible a unos pocos, poseedores de la "imagen interna, que según Durero, es señal del divino artista". ${ }^{11}$ Aquí reside una de las claves mitificadoras del artista: si Dios creo al hombre a su imagen y semejanza, aquellos que pueden reproducir tales representaciones deben haber sido tocados por la divinidad. Múltiples consideraciones y bibliografías apoyan la sentencia de que Dios y el artista mantienen una estrecha relación, de las que se siguen encontrando ejemplos al revisar bibliografías de artistas de principios del siglo XX (recordemos sentencias de artistas como Malévich, que incluso llegó a proclamar que veía la cara de Dios en sus cuadros). De este modo, el quid de la cuestión reside en el concepto de «imagen interna», idea fuertemente relacionada con el origen de la figura de la inspiración. Pensemos en un artista tipo en su estudio tipo, trabajando.

En nuestro imaginario aparece «la imagen de un artista que crea su obra llevado de un impulso incontrolable, en una mezcla de "furia y locura parecida a la intoxicación" ${ }^{12}$ - aquí veo relación directa con la idea construida por las vanguardias de un artista en conexión con el acto creativo a través del consumo de estupefacientes-. Según lo dicho, la inspiración del artista se interpreta socialmente como un éxtasis, como momento de lucidez espiritual a partir del cual es capaz de expresar La Verdad que lleva consigo, inalcanzable para el resto. Esto justifica la opinión forjada durante el Renacimiento de que «la creatividad artística no está determinada por el aprendizaje o la práctica, sino por una cualidad especial» ${ }^{13}$ otorgada de forma divina. Así se genera la más fuerte de las consideraciones que muestran al artista como genio.

El segundo factor determinante que sirve de apoyo para la difusión del mito del artista viene de la mano de la figura secundaria del mecenas, que representa el descubrimiento del don del artista, apoyada más adelante por el biógrafo y el espectador. Esta figura es la que afecta a la construcción del imaginario del artista a través de la transformación de la anécdota en mito (segundo de los factores

9 KRIS, E. \& KURZ, O. Op. cit., p. 31.

10 En el caso de que se desee ampliar tal información en relación a fechas y ejemplos prácticos, recomiendo el capítulo "Conversión del artista en héroe en las biografías", que puede encontrarse en La leyenda del artista. p. 31 - 62.

11 KRIS, E. \& KURZ, O. Op. cit., p. 31.

12 Ídem, p. 86.

13 Ídem, p. 55.

14 Ídem, p. 56.

15 Ídem, p. 104. 
que el análisis de las biografías pone en evidencia), y parte de la consideración de que, debido a ese don divino, el artista posee una superioridad mental y un virtuosismo fuera del alcance del profano. Esta creencia llevó consigo una serie de anécdotas convertidas posteriormente en fórmulas biográficas cuyo fin encubría siempre la necesidad de hallar la imagen del artista en el trabajo del mismo, es decir, la necesidad de "relacionar el carácter del artista con el de su obra y de adivinar la naturaleza del primero a través de la segunda". ${ }^{14}$ Partiendo de esta suposición, el artista llegó a tener un poder absoluto y cuasi mágico sobre su obra, ya que al tratarse ésta de la expresión de su alma, artista y obra eran uno solo. Sucede entonces que, si aceptamos el hecho de que la obra de arte es fruto consecuente de la "divinidad interior" del artista, ésta se convierte en reflejo de la individualidad y singularidad de su creador. Esto justificaría la eterna rivalidad entre artistas y el recelo por revelar los misterios de la técnica, que se sitúa como sinónimo de su ge- nialidad individual, y que se ha transmitido hasta nuestros días en forma de un respeto excesivo por la obra maestra, que puede ser admirada pero nunca tocada sin permiso de su creador.

Y a propósito de la tan común necesidad social de veneración del objeto artístico, surge la necesidad de destacar otro factor que el profano admira notablemente y que apoya una vez más tal apreciaFig.2

Maurizio Cattelan, Untitled [A perfect day], (1999).

En varias de sus obras, Maurizio Cattelan subvierte el papel del galerista, que pasa de promotor del artista bufón o caricatura. Si la función del galerista/mecenas fuera la de descubrir la genialidad del artista (que permanece sumiso y acata las exigencias expuestas por el otro) Cattelan altera esta relación de poder colocando a sus marchantes en situaciones incómodas y que, en ocasiones, evidencian una pérdida de prestigio.

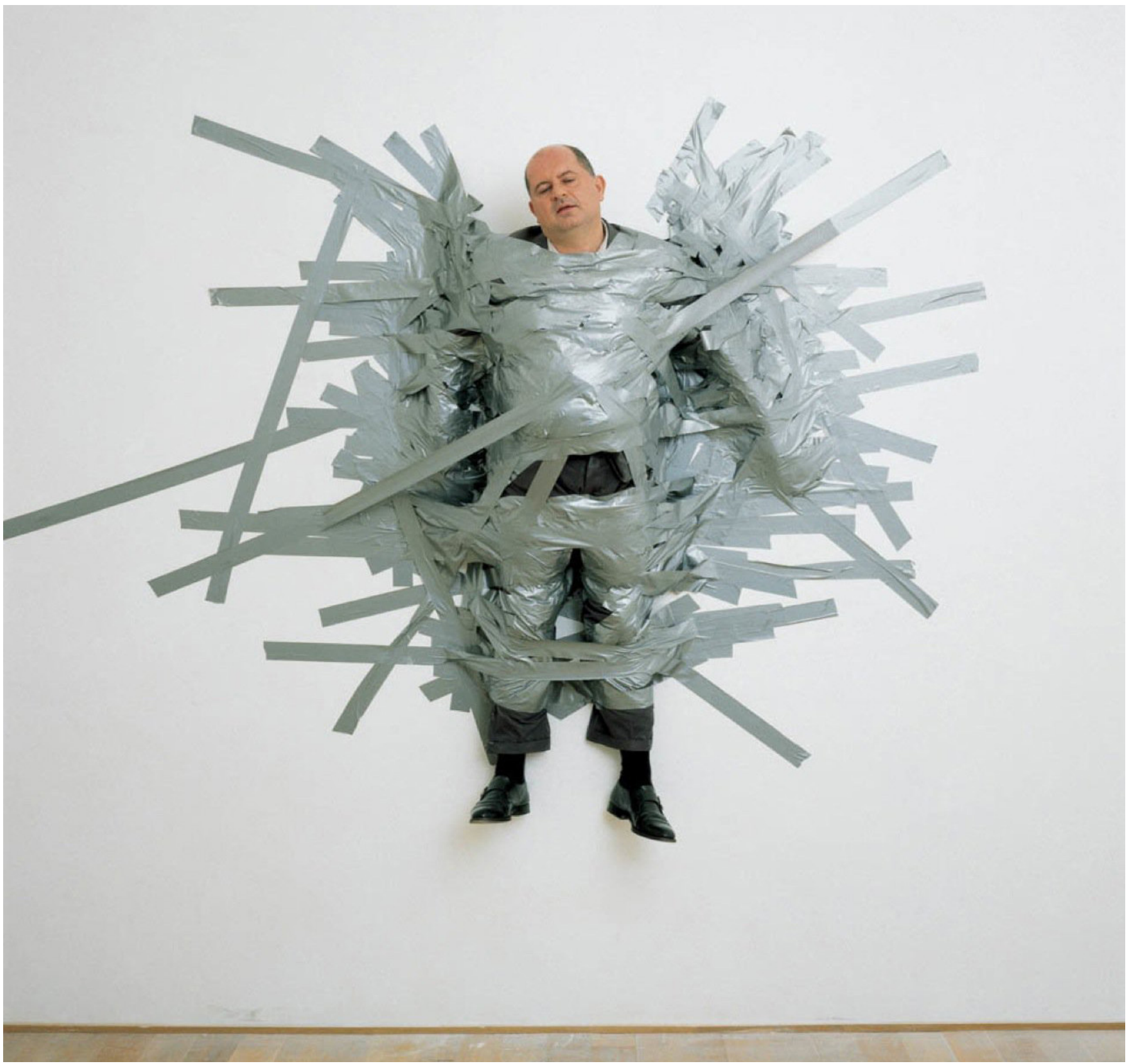


ción: la "genuina capacidad de encantamiento" de la obra de arte. Partiendo de tal consideración, su función se desvela como la de "agitar espiritualmente" al espectador, que queda arrebatado por la revelación expuesta ante sus ojos. Un buen ejemplo de ello es el «relato que apareció en 1552 en el Marmi de Antonfrancesco Doni, que describe la impresión que produjo la Sagrestia Nouva y que ya tuvo amplia difusión en tiempos de Miguel Ángel».

\section{(...la concepción del artista como genio viene dada por la capacidad de éste en transformar un material común en un objeto bello y único.)}

Hasta ahora, he intentado exponer cómo la consideración de que la obra es "hija" directa del artista ha ayudado a su mitificación a partir de la creencia de que tales actividades pueden ser ejecutadas sólo por aquellos predestinados a serlo por deseo divino. De este modo podría llegarse a la conclusión de que la concepción del artista como genio viene dada por la capacidad de éste en transformar un material común (véase el pigmento para la pintura, el mármol para la escultura; y así infinidad de ejemplos) en un objeto bello y único. Pero si ampliamos el campo de miras seremos capaces de percibir, a modo de reflexión final, que "las historias que se cuentan sobre los artistas en todos los tiempos y latitudes reflejan una respuesta humana y universal a la magia misteriosa de la creación de una imagen"16 y la necesidad de veneración que ello nos provoca. Es a partir de este punto en el que considero, apoyándome en las ideas de E. Kris y O. Kurz, que el biógrafo se convirtió en profeta, y la biografía, en mito.

\section{La necesidad de fuga de la Modernidad}

Es bien sabido que el arte contemporáneo (periodo que, según el público de masas, comienza con las vanguardias históricas y se extiende hasta nuestro presente) es un género obtuso para cualquier espectador no especializado. Para Suzi Gablik este recelo surge a causa de la idea instaurada durante la Modernidad de que el arte está hecho solo para una pequeña élite, que conllevó una ruptura en el diálogo entre artista y espectador que sigue sin resolverse. La causa principal de tal afirmación se basa en la autonomía que el arte de principios del siglo XX experimentó, atraído por el descubrimiento de sí mismo y desencantado por su presente. A modo de bisagra entre la concepción del mito del artista y su intento de desmitificación, considero necesario analizar el paradigma de la
Modernidad y llegar a entender las contradicciones que el inicio del siglo XX dejó como legado a la Historia del Arte.

Antes de entrar en materia me interesa dejar claro que al referirme a las contradicciones de la Modernidad lo hago desde la perspectiva de la inestabilidad que el sistema de valores artístico vivía desde finales del siglo XIX, que explosionó durante las primeras décadas del siguiente siglo, y cómo artista y público se dividieron en esferas aparentemente indisolubles. En absoluto pretendo, por el contrario, poner en tela de juicio la apreciación histórica acerca de los hechos sucedidos, ya que los juicios de valor sobre los movimientos artísticos surgidos durante la Modernidad quedan fuera del cometido de esta investigación. Mi interés reside entonces en una relectura que atienda en exclusiva al fin concreto del proyecto: la construcción social de la figura del artista. Aclarado el uso del término y desembarazado de su posible carga negativa es cuando me veo capaz de relacionar cómo la Modernidad continuó fomentando la leyenda del artista al mismo tiempo que empezaba a desacreditar su figura.

Cuando el arte se independizó de la forma a principios del siglo XX lo hizo también de su entorno social en actitud de rebeldía, en gran parte a "consecuencia de la inquietud espiritual del artista ante las sociedades capitalista y totalitaria"17 desarrolladas tras la I Guerra Mundial. La "deshumanización" que el arte de la modernidad vivió durante su periodo álgido, entre 1910 y 1930, transformó la actividad artística en un producto puramente estético e individual, carente de vínculos externos. Así lo afirma Suzi Gablik en ¿Ha muerto el arte moderno?:

2Para una persona comprometida con la modernidad, la salvación del arte está en su autosuficiencia. La experiencia estética es, en sí misma, un fin que merece la pena alcanzar. El arte sólo puede conservar su carácter si se distancia del mundo social; si se mantiene puro."18

Atendiendo a su palabras llegamos a la conclusión de que para los artistas del modernismo el arte debía ser autónomo e independiente, llegando al extremo de considerar que todo aquello que se hiciera con un objetivo funcional dejaba de ser arte. Consecuentemente, la obra se entendía como un "mundo independiente de creación pura, con una identidad propia, fundamentalmente espiritual"19. El inconformismo del artista por lo socialmente impuesto (el estado, la religión, y a fin de cuentas, el arte supeditado a la forma) llevó consigo a un estado de introspección en el que el sentido de ser del arte residía en el arte mismo. "Este encerrarse en sí mismo, 
la convicción de que, para realizarse, había que encontrarse con uno mismo, inspiró casi una teodicea del individuo a comienzos de la modernidad"20, que continuó alimentando la figura de un artista en conexión con el acto creativo por medio del éxtasis de la introspección y el reflejo de la individualidad del artista en sus creaciones. Vuelvo a recordar cómo para muchos artistas de principios de siglo la abstracción era, incluso, una teología estética que conectaba al artista con la figura directa de Dios, relacionando la mística y lo sublime con la práctica artística, y aumentando así la carga de significado del mito del artista. A causa de la búsqueda de la libertad y autonomía del propio arte, y del grado de introspección y abstracción por parte de los artistas, el público se sintió fuera de la definición del arte, puesto que durante la Modernidad el arte mismo (sus representantes, conformados por una élite de artistas e intelectuales) rechazaba formar parte de la sociedad.

En este caso se ve claro cómo es el artista moderno quien, por decisión propia, decide romper la relación con el público. De hecho, hay numerosas citas y entrevistas en el que se aprecia cómo el espíritu del artista moderno no contemplaba al espectador. Para Clifford Still, por ejemplo, "pintar era el único y último acto de libertad que podía prevalecer sobre la política, la ambición y el comercio" $^{21}$. El arte cumplía entonces la única función de satisfacer las necesidades de su creador. Más que como diálogo entre un yo-creador y un tú-receptor, existía una relación entre un yo-obra y un tú-creador, en la que la obra se situaba como ente independiente que se generaba gracias a la ayuda del artista pero de forma autónoma; como aparición ensimismada, como revelación mágica.

Si aceptamos que la búsqueda de la singularidad y la autonomía han conseguido alejar al arte del marco social, podríamos llegar a entender la consideración popularmente instaurada que entiende el arte moderno como una burla, ya que una vez que los valores de destreza artísticos establecidos hasta el momento, tales como el virtuosismo técnico y la fidelidad a la naturaleza, han desaparecido, el público carece de referencias estéticas. Sucede entonces que «para el público en general — tal como diría Suzi Gablik—el arte moderno siempre ha supuesto una pérdida de destreza, un fraude o una burla. De hecho, podemos aceptar de buen grado nuestra ignorancia de un idioma extranjero, o del álgebra, pero en el caso del arte es más probable, como señaló en una ocasión Roger Fry, "que la gente, ante una obra que no le gusta y que no puede comprender, piense que se hizo expresamente para insultarla. Una de las características más perturbadoras del arte moderno sigue siendo la sensación de fraude que desde un principio le ha pesado como una losa”. ${ }^{22}$ Lamentablemente, analizar los pormenores de esta sensación generalizada nos llevaría por otros derroteros que aunque interesantes, se salen del esquema de la investigación. Aquí, mi interés en exponerlos reside únicamente en hacer ver cómo a partir de las vanguardias históricas se ha reconsiderado la figura del artista, que ha pasado de lo fascinante a lo difícilmente penetrable, pero que no por ello ha devaluado la imagen de su leyenda, que debido a la filosofía del arte por el arte sigue pensando al artista como ser místico cuyo don inherente y misteriosa complejidad lo posicionan en un estrato mágico y ajeno a toda consideración social.

\section{Ser artista es la decisión de ser artista}

Para Lucy Lippard ${ }^{23}$, a mediados de los años sesenta el panorama artístico se encontraba inmerso en una agitación ideológica que arremetía en contra de la carga de significado asociada a la figura del artista y al status de la obra de arte como mercancía. A la consideración de superioridad del artista se le sumaba la consideración de lujo del objeto artístico, transformado en objeto de deseo por el capitalismo exacerbado. Las primeras manifestaciones de lo que posteriormente se conoció como Arte Conceptual surgían en medio de tal conmoción, abogando por un arte que, a grandes rasgos, se caracterizaba por la imposición de la idea sobra la forma, posicionándose ésta como "secundaria, de poca entidad, efímera, barata, sin pretensiones y/o desmaterializada"24. Esta postura llevó consigo una estética que, tal y como podemos leer en Arte desde 1900,

pone en juego una crítica de la noción moderna de visualidad (u "opticalidad"), definida como una esfera independiente y autónoma de la experiencia estética. Pero, además, está en cuestión la problemática cualidad única del objeto artístico, así como el nuevo medio de distribución (el libro, el póster, la revista) y la "especialidad" de ese objeto, es decir, el rectángulo pictórico o el sólido escultórico. ${ }^{25}$

Aquí, la indiferencia estética justificaba toda una reflexión sobre "lo que se suponía que era el arte y el punto a que había llegado" ${ }^{26}$ que recuperaba la figura del espectador, pero que le exigía una posición activa y crítica. Para los militantes y defensores del conceptual este hecho supuso un posicionamiento contestatario que devaluaba la fisicidad de la obra de arte, preguntándose por los límites de la actividad de mirar, y convirtiéndose ésta en un "puente entre lo verbal y lo visual". ${ }^{27}$ Las representaciones conceptuales rechazaron lo visual y los con-

21 Clifford Still en Ídem, p. 23.

22 Ídem, p. 13.

23 Véase "Intentos de Escapada» en LIPPARD, Lucy R. Seis años: La desmaterialización del objeto artístico desde 1966 a 1972. Ediciones Akal.

Madrid, 2004. p. 7 - 29.

24 LIPPARD, Lucy R. Op. cit., p. 8.

25 FOSTER, Hal et al. Arte desde 1900. Modernidad, antimodernidad y posmodernidad. Ediciones Akal. Madrid, 2006. p. 528.

26 LIPPARD, Lucy R. Op. cit., p. 7.

27 Ídem, p. 12 
ceptos tradicionales de la producción artística, definiéndose infieles e indiferentes al medio, obviando la exclusividad del original y usando técnicas de apropiacionismo y tergiversación tanto de la historia del arte como de otros discursos, como el literario, el poético o incluso el judicial. Y es que la estética predominante arremetía contra lo aurático de la obra de arte, eliminando todo atisbo de manierismo a favor de la sobriedad y la impersonalidad. El sello del artista ya no estaba en la individualidad de la gestualidad, sino en la del discurso: "la idea se convierte en una máquina de hacer arte"28, diría LeWitt en 1967. Las palabras de Lucy Lippard al respecto ayudan a esclarecer tales consideraciones, ya que afirman que

"este ataque a la idea de originalidad, al toque del artista y a los aspectos competitivos del estilo individual constituía un ataque a la teoría del genio, el aspecto más querido hasta entonces del arte patriarcal de la clase dirigente." ${ }^{29}$

Analicemos más detenidamente lo dicho hasta el momento. En primer lugar, encontramos la necesidad de "desmaterialización del objeto artístico", idea introducida por Lucy Lippard en Seis años: La desmaterialización del objeto artístico desde 1966 a 1972, que impone un arte en el que la idea supera la forma, devaluándola a partir de una indiferencia estética y un consecuente sacrificio de la destreza técnica o "desespecialización", concepto definido por Ian Burn en su texto The Sixties: Crisis and Aftermath (Or the Memoirs of an Ex-Conceptual Artist). Esta desespecialización lleva consigo la disolución de los límites de la obra de arte como objeto producido manualmente, que ve su máxima expresión en el ya clásico readymade duchampiano y en la capacidad de reproductibilidad mecánica que Walter Benjamin dilucidó por primera vez en 1935 con su ensayo La obra de arte en la época de su reproducción mecánica, que proponen al objeto artístico como ente no único e inespecífico ${ }^{30}$. Pero vayamos por partes.

Cuando Duchamp tuvo la intencionalidad de colocar el urinario bocabajo y transformarlo en la archiconocida Fountain, legó a las generaciones venideras la capacidad de desdibujar los límites del objeto artístico y definir la idea propia del arte por el simple hecho de nombrarlo. El poder del objeto artístico residía, consecuentemente, en la decisión del artista, y ambos se rearticulaban como representación de la actitud y posición ante el acto creativo. De este modo, el objeto final pasaba a un segundo plano, supeditado a la actitud crítica del artista por "nombrar y contextuali- zar" el arte y sus dispositivos de presentación -esto es arte porque se denomina como tal y porque se expone donde socialmente se entiende que debe haber arte. Esta nueva consideración (que, no olvidemos, aparece en 1917, principios de las vanguardias históricas, y aún a día de hoy se nos establece como referencia) dejaba de lado la "manualidad" del artista que, de hacer algo, era únicamente el hecho de señalar que ahí había arte. Por otro lado, la idea de un arte que se define por ser seriado, no único y consecuentemente, no original, apoya una vez más el desvanecimiento de la individualidad del artista y pone sobre la mesa la discusión de si una obra sin original puede ser plagiada y, por lo tanto, de si las ideas preconcebidas de autoría y propiedad siguen teniendo validez. En una clara relectura del concepto de reproductibilidad mecánica de Walter Benjamin, los dispositivos artísticos se ampliaron, aceptando que los medios mecánicos pudieran materializar el desarrollo conceptual llevado a cabo por el artista en una búsqueda por la "desespecialización” del resultado artístico.

Para una mejor comprensión del significado de este término, podríamos apoyarnos en las palabras encontradas en Arte desde 1900 que describen la desespecialización como el deseo de «eliminar la competencia artesanal y otras formas de virtuosismo manual del horizonte de la producción artística y de la evolución estética» ${ }^{31}$. Casualmente, la última de las manifestaciones artísticas analizadas en el texto de Ian Burn anteriormente citado es el readymade, a partir del cual "la producción colectiva del objeto mecánico y producido en serie ocupó el puesto de la obra excepcional creada por el virtuoso"32 $^{32}$. Es decir, al posicionar un objeto realizado por un otro - ajeno a la concepción de obra de arte- como objeto artístico, el acto creativo se colectiviza, puesto que el producto es resultado de quien lo ejecuta y quien lo piensa, poniendo sobre la mesa conceptos tales como el de autoría. Pero volviendo a la naturaleza del término, lo que preocupaba a quienes abogaban por la desespecialización del arte era, en esencia, la destrucción de la teoría del artista como genio a través de la eliminación de su figura sobre la obra de arte.

\section{Es cierto, y debemos ser conscientes de ello, que una pérdida de la destreza técnica no es contraria a la concepción de la obra como ente único.}

28 LEWITT, S. citado en Ídem, p. 17.

29 Ídem.

30 Aunque la postura de Walter Benjamin posicionaba al decadente arte de la pintura y la escultura en contra del nuevo arte de la fotografía y el cine, casi considerándolo el arte del nuevo presente, a día de hoy este ensayo ha contaminado todas las esferas del arte, y nos servirá para hablar de cómo el arte conceptual fue consciente del poder y la signi cación de la obra no-única; en BENJAMIN, Walter. La obra de arte en la época de su reproducción mecánica. Casimiro libros. Madrid, 2010.

31 FOSTER, Hal et al. Op. cit., p. 531.

32 Ídem. 
De hecho, ninguno de los conceptos analizados lo es, ya que a día de hoy, y haciendo recapitulación de la filosofía de los años sesenta y setenta, nos damos cuenta de cómo el mercado ha aprendido a comercializar la obra seriada o «inmaterial». Pero lo interesante es cómo el surgimiento de tales preocupaciones llevó a la práctica de una serie de "ejercicios" que luchaban por hacer ver las taras de un arte aún supeditado al mito del artista- genio. No hay más que leer las palabras de Lucy Lippard allá por 1969, que nos devuelven a la necesidad utópica de sinceridad artística por la que tanto lucharon los artistas conceptuales:

Los artistas que tratan de hacer arte no objetual están dando una solución drástica a la cuestión de que los artistas sean comprados $\mathrm{y}$ vendidos tan fácilmente junto con su arte [...]. Las personas que compran una obra de arte que no pueden colgar o tener en su jardín no tienen tanto interés en la posesión. Son patrones más que coleccionistas. ${ }^{34}$

Sin originalidad (ni objetual ni aurática), el valor icónico del objeto artístico se supone extinto, y las referencias de valorización (especialmente en cuanto al sistema mercantilista), se tornaban complejas de definir. Si no había objeto, se suponía que tampoco había posibilidad de poseer. Este proceso es el que se definía como "desmaterialización" del objeto artístico, y que postulaba un arte basado en la información y los sistemas que reemplazó a las preocupaciones formales tradicionales. Aún así, la desmaterialización no exigía una inmaterialidad física, sino más bien una independencia de la forma premeditada, en el caso de haberla; una vez más, la superposición de la idea sobre el objeto.

Lo interesante de estos cuatro conceptos, más allá de si dieron el resultado esperado o no, es cómo rebaten la idea renacentista del artista tocado por la divinidad. Si cualquier objeto puede considerarse artístico y la destreza técnica deja de ser sinónimo de la calidad del artista, perdemos las referencias de valor a la hora de distinguir al artista del no-artista, ya que proponen que ser artista es simplemente la decisión ser artista. Aceptando tal afirmación, el su-

Fig.3

John Baldessari, Commissioned painting: a painting by Edgar Transue, (1969).

El origen de la serie Commissioned Paintings surgió de la declaración crítica de Al Held, que promulgaba que el arte conceptual era simplemente señalar cosas. Tomándose de forma literal tal sentencia, Baldessari decidió tomar fotografías de la mano de su amigo George Nicolaidis señalando diversos objetos aleatorios. Una vez rebeladas las imágenes, contrató los servicios de diversos pintores locales con la idea de que reprodujesen cada una de las escenas de la forma más fiel posible. Cada lienzo muestra, además, el nombre del autor de la obra. 
puesto de la genialidad del artista desde su nacimiento y la idolatría de su capacidad concedida mágicamente se vuelven irrelevantes, ya que la única diferencia sustancial entre la vida de un artista y la de la cualquier otro individuo es simplemente la decisión de que su actividad productiva se encuadre dentro del sistema del arte.

\section{Fig.4}

Sherrie Levine. Fountain (After Marcel Duchamp), (1991).

Sherrie Levine exploró los límites de la concepción de la figura del artista mediante la apropiación exacta de obras de reconocidos artistas (que además de artistas, eran exclusivamente hombres). Su única incorporación se hallaba en el título, que automáticamente reinterpretaba el contenido. Al apropiarse no solo de un gesto, sino de una obra completa, se ponía de manifiesto los límites de la labor del creador y su autoridad para nombrar arte.

\section{BIBLIOGRAFÍA}

BENJAMIN, Walter: La obra de arte en la época de su reproducción mecánica. Madrid, Casimiro libros, 2010.

FOSTER, Hal: El retorno de lo real. La vanguardia, anales de siglo. Madrid, Ediciones Akal, 2001.

FOSTER, Hal et al.: Arte desde 1900. Modernidad, antimodernidad y posmodernidad. Madrid, Ediciones Akal, 2006.

GABLIK, Suzi: ¿Ha muerto el arte moderno? Madrid, Herman Blume, 1987.

KRIS, Ernst y KURZ, Otto: La leyenda del artista. Madrid, Ensayos Arte Cátedra, 2010.

LIPPARD, Lucy R.: Seis años: La desmaterialización del objeto artístico desde 1966 a 1972. Madrid, Ediciones Akal, 2004. 


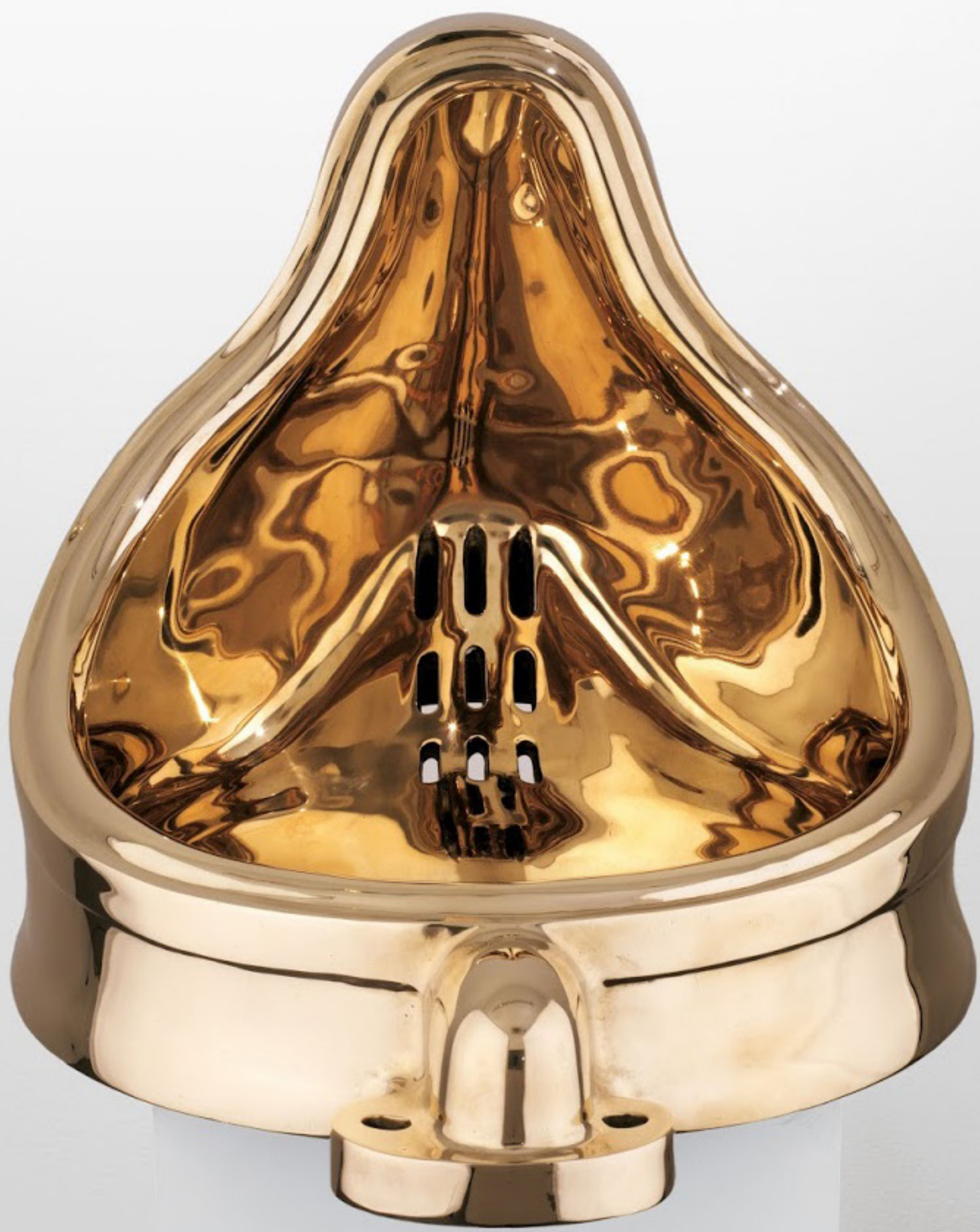

